\title{
PRIMARY IDENTIFICATION OF EUCALYPTUS (Eucalyptus camaldulensis) WOOD LIGNIN MONOMERS BY FT-IR SPECTROSCOPY
}

Esam Mohammed Sheet Sheet Mohammed Saleh Ali Younis Hamed Commission of Tech. Education, Inst. of Tech. Education / Mosul

\begin{abstract}
Lignin samples were isolated from Eucalypt wood (Eucalyptus camaldulensis) by kraft process, and then all samples were examined and tested with Fourier Transform Infrared Instrument Technique for identifying the types of lignin monomers units from their spectra.The Lignin monomers spectra chart showed these peak bands( 616.80, 795.11, 876.96, 1057.14, 1127.19, 1458.74, $1509.21,1542.05,1636.26,1735.68,2863.72,2922.35,2967.95,3447.01$, and $3650.56 \mathrm{~cm}^{-1}$ ).No evidence for methoxyl group bands were observed, though all monomers of the tested lignin in this investigation which obtained from Eucalypt wood by KRAFT process consist mainly of P-hydroxy phenyl propane units.
\end{abstract}

\section{INTRODUCTION}

Fourier Transform Infrared spectroscopy (FT-IR) is an analytical technique used to identify the functional groups of the organic (and in some cases inorganic) materials. This technique measures the absorption of various infrared light wave lengths by the materials interest. These bands identify specific molecular components and structures (Silverstein and Webster, 1998). The first astronomical application of Fourier Transform spectroscopy experinced in the late 1950's and early 1960's when J. cones and coworkers obtained high resolution and high quality spectra. To day commercial Fourier Transform Infrared spectrometer are widely available aided by fast computers which perform Fourier Transforms in flash, vise infrared (Socrates, 1994).

Recently the Fourier Transform Infrared (FT-IR) is used as a fast, reliable and easy analytical tool for wood and wood derivatives because of its improved spectral quality and is meaning full difference spectra which can be obtained even in region of high background absorption and the ability to detected small changes in bands overlapped by strong bands undergoing (Rutherford etal., 2004).

Lignin is after cellulose, the principal constituent of wood structure of higher plant.

Infrared spectroscopy in the near IR region wave length $2.5-1.5 \mu \mathrm{m}$, wave number $4000-600 \mathrm{~cm}^{-1}$ is useful as physical method for characterizing lignin and its derivatives, and their spectrum is characteristic property of compound with exactly known structures ,there are several uncertainties with the interpretation of lignin IR ,the variation in lignin structures and compositions due to the origin sample ,the isolation procedure are the causes of different spectra measuring of lignin(Alobydi etal.,2004).

Fengel and Wegener(1989) give the elemental composition and methoxy content of the analytical and technical lignin isolated from Eucalyptus regnons, 
the results show $56-60 \%$ of carbon content and the methoxy contents reach to 18 $22 \%$,

these

Received 29/ 10 /2006 accepted 7/3/2007.

results differed than the carbon content of the softwood lignin which reaches about $60-65 \%$ where as therefore, IR spectra of lignin shows several major absorption bands which can be assigned empirically to structural groups.

Chemists cleared that the empirical formula of lignin based on a phenyl propane (C9)unit is $\mathrm{C}_{9} \mathrm{H}_{8.83} \mathrm{O}_{2.37}\left(\mathrm{OCH}_{3}\right)_{0.96}$ in coniferous lignin , and $\mathrm{C}_{9} \mathrm{H}_{8.9} \mathrm{O}_{3}\left(\mathrm{OCH}_{3}\right)_{1.45}$ in deciduous lignin and it appears that there are about 3 sringyl propane unit for every 2 guaiacyl propane units in deciduous lignin (Sarkanen etal.,1967).

So for the all reasons above our investigation was put to study the different absorption bands of the Kraft lignin extracted from Eucalyptus camaldulensis by using the Fourier Transform Infrared technique and to find out and identify the structural units and the functional groups of it.

\section{MATERIALS AND METHODS}

Wood \& wood cooking: A $\log$ at about $1.5 \mathrm{~m}$ of Eucalyptus camaldulensis was bought from a local Mosul markets, then it was barked and chipped with a multiknifes chipper in one of a local industry according to (ASTM-584, 1968).All chips were screened by vibration tray at about $1.6-2.2 \mathrm{~cm}$ in size. $5000 \mathrm{gm}$ of the chips had been randomizing obtained and subjected in a digester in the technical institute of Mosul (Othmer, 1967).

A white liquor was made by mixing $250 \mathrm{gm}$ of sodium sulphate -5 -hydrate $\mathrm{RS}, 550 \mathrm{gm}$ of potassium hydroxide powder, $250 \mathrm{gm}$ of sodium carbonate, and 30 liters of tape water, the liquor added to the wood chips in the digester and the cover of the digester closed tightly, then the mixture was cooked in the digester for $5 \mathrm{hrs}, 160 \mathrm{C}^{\circ}$, and at ( 7 bars) pressure. After the completing of the digestion periods the black liquor was separated from the digested wood chips.

The black liquor was Acidified by sulfuric acid (72\% Conc.) which was added to it at several batches to reduce the $\mathrm{pH}$ level in the black liquor from $(\mathrm{pH} 12)$ to $(\mathrm{pH}$ 8)at this point the acidification was stopped at and at that level the precipitated Kraft Lignin had been seen at the bottom of the container. The precipitated Lignin was separated by decantation and washed for several times by water then put in oven for $24 \mathrm{hrs}$ for drying it at $50 \mathrm{C}^{\circ}$.

Infrared spectroscopy: Several samples of Eucalypts Kraft Lignin with potassium bromide pellets were made. Each sample was prepared by milling (5 milligram) of the extracted lignin and pressed with potassium bromide to form apellet from each other (Gracin, 2001).

The fourier transform infrared spectrophotometer of the name Tensor 27 Broker co., Germany. The ratio of 1:100 was used as infrared source with the adenterated triglycine sulfate detector. This instrument was scanned from 4000 to 
400 reciprocal centimeters $\left(\mathrm{cm}^{-1}\right)$; averaging to scans at $1.0 \mathrm{~cm}^{-1}$ interval with a resolution of $4.0 \mathrm{~cm}^{-1}$.All spectra were normalized after acquisition to a maximum absorbance.

\section{RESULTS \& DESCUSSION}

The FT-IR spectra of the Eucalyptus Kraft Lignin samples showed typical absorption bands. Figure (1) shows all spectra band result an FT-IR chart, where as table (1) summarizes all wave numbers of the peak absorption monitored in Figure (1) with there corresponding descriptions and intensities.

As it is shown in Figure (1) and table (1), the first peak absorption is at the fingerprint region of about $616.80 \mathrm{~cm}^{-1}$ which is mean a bending vibration in an out plane of $\gamma \mathrm{C}-\mathrm{H}$ involving in the aromatic ring of the Lignin monomers with weak intensity, this result is accepted with Haw and Schultz (1985), and Wallis etal. (1996) indicates the region between $670-580 \mathrm{~cm}^{-1}$ which involve ion vibrations of $\mathrm{SO}_{4}$, sulfide, mercaptan with medium intensity.

Table (1): Vibration descriptions, frequencies, and the intensities of lignin monomers .

\begin{tabular}{|c|c|c|}
\hline Description & Frequency, $\mathrm{cm}^{-1}$ & Intensity \\
\hline $\begin{array}{l}\text { Bending vibration in }(\gamma \mathrm{CH}) \text { in out of } \\
\text { plane of the aromatic ring of the } \\
\text { lignin monomers. }\end{array}$ & 616.80 & Weak \\
\hline $\begin{array}{l}\text { Stretching vibration for methyl } \\
\text { groups }\left(\mathrm{CH}_{3}\right) \text {. }\end{array}$ & 795.11 & Strong \\
\hline $\begin{array}{l}\text { Bending vibration for hydrogen } \\
\text { atoms in an out plane of the phenyl } \\
\text { ring. }\end{array}$ & 876.96 & Strong \\
\hline $\begin{array}{l}\text { Stretching vibration for } v(\mathrm{C}=\mathrm{O}) \text { of } \\
\text { the alcohol. }\end{array}$ & 1057.14 & Broad \&Shoulder \\
\hline $\begin{array}{l}\text { Stretching vibration of the ether } \\
\text { groups. }\end{array}$ & 1127.19 & Weak \\
\hline $\begin{array}{l}\text { Stretching vibration of } \quad v(C=C) \\
\text { in the aromatic ring. }\end{array}$ & $\begin{array}{l}1458.74 \\
1509.21 \\
1542.05\end{array}$ & Medium \\
\hline $\begin{array}{l}\text { Stretching (nonconj) vibration band } \\
\text { for } v(C=C) \text { in aliphatic chain. }\end{array}$ & 1636.26 & Medium \\
\hline $\begin{array}{l}\text { Stretching vibration of the aliphatic } \\
\text { aldehyde and ester groups. }\end{array}$ & 1735.68 & Very weak \\
\hline $\begin{array}{l}\text { Stretching vibration for methylene } \\
\text { groups. }\end{array}$ & $\begin{array}{l}2863.72 \\
2922.35\end{array}$ & Medium \\
\hline $\begin{array}{l}\text { Asymmetric Stretching of methyl } \\
\text { groups. }\end{array}$ & 2967.95 & Medium \\
\hline Stretching vibration for hydrogen & 3447.01 & Very strong and broad \\
\hline
\end{tabular}




\begin{tabular}{|l|l|l|}
\hline bonds in lignin monomers. & & \\
\hline $\begin{array}{l}\text { Stretching vibration for free } \\
\text { separated alcohol and phenol. }\end{array}$ & 3650.56 & Strong and sharp \\
\hline
\end{tabular}

The second peak band is at $795.11 \mathrm{~cm}^{-1}$ level in the same figure give a description of the methyl stretching vibration with strong intensity, the result agree with (Pandey, 1999), while and Raymond (2004) said that the region between $800-770 \mathrm{~cm}^{-1}$ mentioned to the substituted meta- di of the aromatic ring in Lignin.

The peak band at $876.96 \mathrm{~cm}^{-1}$ monitors the bending vibration of the hydrogen atoms at an out of the plane of the phenyl ring in Lignin units, however, Kotilainen etal.(2000) describes the absorption with a weak intensity in region between $890-820 \mathrm{~cm}^{-1}$ of the aliphatic peroxides (C-O-O-C) which fragments from lignin at the digestion period of wood chips by Kraft processes, other literatures like (Amen etal.,2001) stressed that the $\gamma \mathrm{C}-\mathrm{H}$ bending vibration at an out plane of the conjugated molecules.

Figure (1) also shows a band at $1057.14 \mathrm{~cm}^{-1}$ which referred to the stretching vibration of alcohol caused by the combination or overlapping of $\mathrm{C}-\mathrm{O}$ as a result of several deformation in lignin by the action of the chemical used in the wood digestions, Kondo(1997) said that the $1100-1000 \mathrm{~cm}^{-1}$ region concerning a sugar or poly saccharide moieties due to the width and the intensity of the resulting band, while the weak intensity of the region between $1070-1000 \mathrm{~cm}^{-1}$ mentioned on the bending of the aromatic mono substituted in plane.

Another band at $1127.19 \mathrm{~cm}^{-1}$ position indicates stretching vibration of ether groups caused by base actions on the wood chips during the cooking period.

Three bands at $1458.74 \mathrm{~cm}^{-1}, 1509.21 \mathrm{~cm}^{-1}, 1542.05 \mathrm{~cm}^{-1}$ levels show also a stretching vibration of $\mathbf{v} \mathbf{C}=\mathbf{C}$ bond in the aromatic ring, these results are in line of White(1994) who found that the IR spectra at $1470-1400 \mathrm{~cm}^{-1}$ range was for C$\mathrm{H}$ deformation and the aromatic ring vibration, but Baldock and Smernik(2002) said that the range between $1613-1471 \mathrm{~cm}^{-1}$ wave numbers gave an indication on the skeletal aromatic ring vibration, therefore, all last results enable us to prove the existence of lignin in the unknown preparations, whereas the band between $1600-1500 \mathrm{~cm}^{-1}$ wave numbers gave us the differentiation between softwood and hard wood Lignin's bands intensities( Faix,1991) .

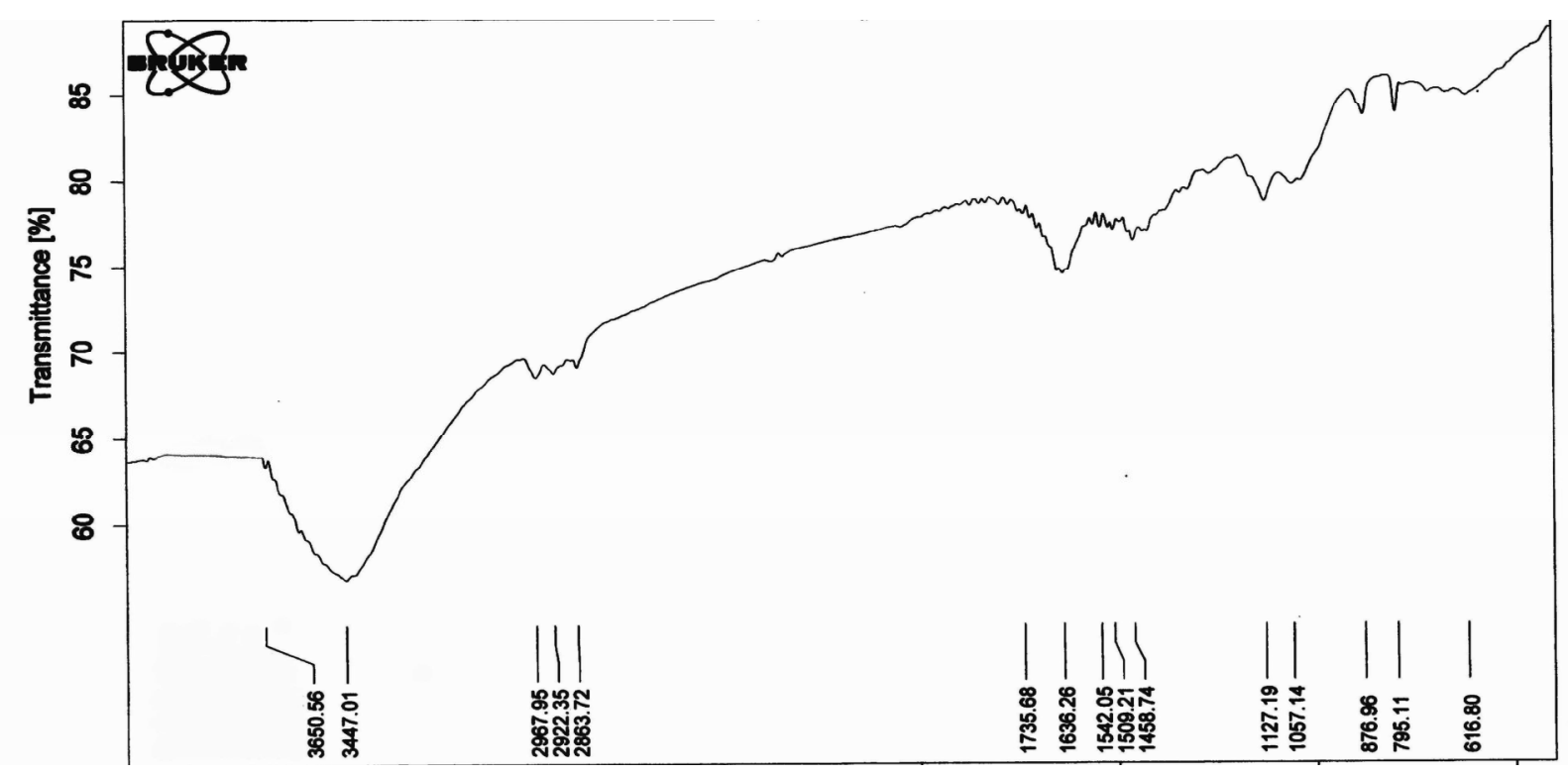


A $1636 \mathrm{~cm}^{-1}$ position shows a broad peak spectrum with medium intensity stretching vibration of $v \mathrm{C}=\mathrm{C}$ of the aliphatic chain with medium intensity because the spectrum of these double bonds in chain appears at the range between 1620$1680 \mathrm{~cm}^{-1}$ with var. intensities, Stark etal. (2004) also saw a broad band of the carbonyl group at $\sim 1600$ region due to the separated carbonyl and carboxyl compound of the elevated temperatures within the digestion periods.

There are also a stretching vibration of the aliphatic aldehyde and ester group at $1735 \mathrm{~cm}^{-1}$ wave number level as we can see in figure (1) and table (1). Because of the Acetyl of uronic ester of the poly saccharids residues appeared at the range between $1740-1735 \mathrm{~cm}^{-1}$ wave numbers and it might be interfered with carbonyl group bands.

Two bands at 2863.72-2922.35 wave number levels show a stretching vibration for the metheylene groups; these results indicate the absence of the methoxyl group's bands which often appears at about the range $2830-2815 \mathrm{~cm}^{-1}$ wave numbers (Alobydi etal. 2004).

The $2967.95 \mathrm{~cm}^{-1}$ wave number peak band show a stretching vibration for the methyl group, because the methyl $\left(\mathrm{CH}_{3}\right)$ group seem always to appear between two distinct bands near $2962 \mathrm{~cm}^{-1}$ and $2872 \mathrm{~cm}^{-1}$, which were described as an asymmetric and symmetric stretching, respectively if several methyl groups are existed in the tested compounds with sevral intensities as it reported by Dam etal. (2004).

A significant band appeared at about $3447.01 \mathrm{~cm}^{-1} \mathrm{w} . \mathrm{n}$. with strong and abroad intensity of stretching vibration refer to intra molecular hydrogen bonds in the lignin monomers, hydroxyl groups, and alcohol's of the lignin units which fragment during the wood digestion period, whereas the absorption bands range of the intra molecular hydrogen bonds are between $3590-3420 \mathrm{~cm}^{-1}$ and caused a cis isomer in the Para hydroxy phenyl structures of the lignin (Kubo and Kadla, 2005).

The last peak band is at $3650.56 \mathrm{~cm}^{-1} \mathrm{w} . \mathrm{n}$. level as figure (1) shows a sharp stretching vibration for the free separated alcohol bonded and phenols from the wood lignin.

From the results and bands obtained above. It can be concluded that the lignin of Eucalyptus camaldulnsis in this study consisted nearly of equal units of ploy hydroxy phenyl propane as it shown in figure (2)with the absence of the 
methoxyl groups because of that the guaiacyl and sringyl units formed the heart of the Lignin polymer whereas the P-hydroxy phenyl propane units form the surface of the polymer in addition to the demethylation of the lignin monomers caused by sulfite ions as it is shown in the model of the reaction in figure (3) due to the higher nucleophility of the sulfite and hydrogen sulfite, which caused a cleavage of some methyl- aryl ether bond depending on the current $\mathrm{pH}$ levels, therefore these results are accepted with Nuopponen etal. (2004).

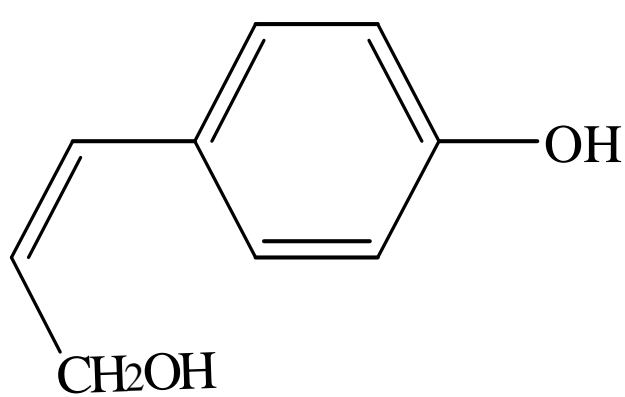

Figure ( 2 ): P-hydroxy phenyl propane unit , the mean monomer of the tested lignin in the study .<smiles>COc1ccc(/C=C/CO)cc1OC</smiles><smiles>COc1ccc(/C=C/CO)cc1[O-]</smiles>

التشخيص الأولي لوحدات لكنين خشب اليوكالبتوس ( Eucalyptus camaldulensis ) البنائية

Figure (3 ): The demEthyllatid) tignin units by sulfiteion علي يونس حامد

$$
\text { عصام محمد شيت }
$$

\section{الخلاصة}

تمكنت الدر اسة من التشخيص المبدئي للكنين المستخلص من أخشاب اليوكالبتوس Eucalyptus camaldulensis 
وتم تحليلها باستخدام المطيافية تحت الحمراء FT-IR لغرض تشخيص الوحدات البنائية المتكون منها

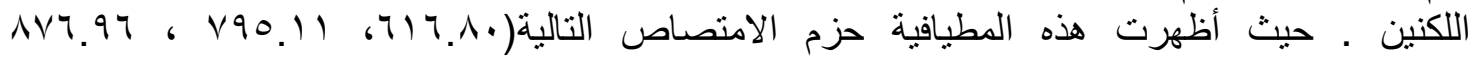

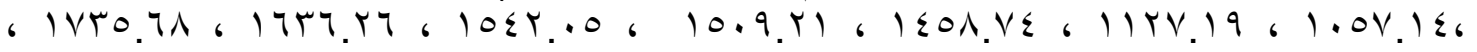
ك T.V

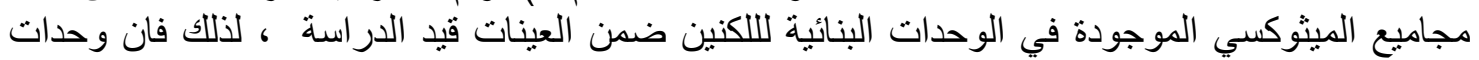

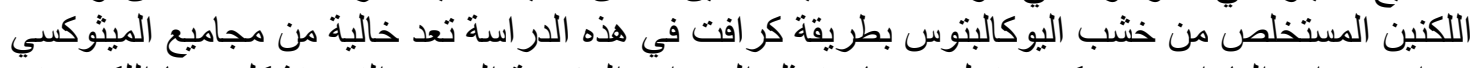

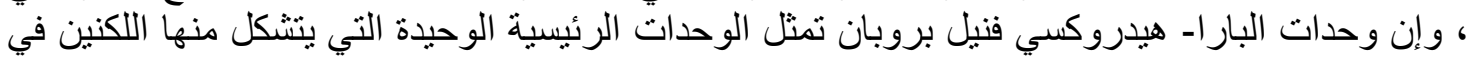
هذه الدراسة . 


\section{REFERENCES}

Amen, Chen.; Carlos. P. Hooshang and Ch.Roy (2001). Production of monomer phenols by thermochemical conversion of biomass, Areview: Boiresource technology. 79: 277-299.

Alobydi, E.M.Sh.; Gh. A.hadi and W. A. Kasir (2004). Using (IR) Spectroscopy in identification of the lignin - extracted from ( populus nigra) wood. Iraqi J. of Agri. sci. 5(4):77-81.

ASTM-C 584 (1968). Annual book of american standard testing material, wood and adhesive. USA.22:601-607.

Baldock, J. A. and R. J. Smernik (2002). Chemical composition and boiavailablity of thermally altered pinus resinosa (red pine) wood. Organic Chemistry. 33:1093-1109.

Dam, V. J.; R. Gosselink. and E. D. Dejong (2004). Lignin Applications. Agrotechnology \& Food Innovations. wageningen university and research centre. netherlands report 2004:20-23.

Faix, O. (1991). Classification of lignin from different botanical origins FT-IR spectroscopy. Holtzforchung. 45:21-27, supplement.

Fengel, D. and G.Wegener (1989). Wood chemistry ultra structure reactions. Wide Gruyter, Berlin. New York PP 155-175.

Gracin, D.; I. Bogdanovic; V. Borjanovic; M. Jaksic; Z. Pastuovic; J.M. Dutta; B. Vlahovic and R. J. Nemanich (2001). Quantitative analysis a-Si1-xCx: H thin films by vibrational spectroscopy and nuclear methods. Vacuum 61(24):303308.

Haw, J. F. and T. P. schultz (1985). Carbon -13 cp./MAS NMR and FT-IR study of low temperature lignin pyrolysis. Holtzfroschung. 39: 289-296.

Kubo, S. and J. F. Kadla (2005). Hydrogen bonding in lignin: A fourier transform infrared model compound study. American Chemical Society. 6:2815-2821.

Kondo, T. (1997). The assignment of IR absorption bands due to free hydroxyl group in cellulose. 4: 281-292.

Kotilainen, R. A.; T. J. Toivanen and R.Alen (2000). FTIR monitoring of chemical changes in softwood during heating. J. Wood Chem. Technol.20: 306-320.

Nuopponen, M.; T. vuorinen.; S. Jamsa. and P.VII. Taniemi (2004). Thermal modification in softwood studied by FT-IR and UV resonance raman spectroscopies. Journal of Wood Chem.and Technol. 24: 13-26.

Othmer, K. (1967). Sulfate,or kraft pulp mill process mainly coniferous wood. Encyclopedia of chemical technology.667-680.

Rutherford, D. W.; L. W. Robert and G. Cox. Larry (2004). Changes in composition and porosity occurring during the thermal degradation of wood and wood components. USGS science for a changing world. scientific Investigation Report 5292.

Pandey, K. (1999). A study of chemical structure of softwood and hardwood polymer by FTIR spectroscopy. J. of Applied Polymer Sci. 71: 1969-1975.

Poke, F.S.; J.K. Wright. and C.A Raymond (2004). Predicting extractives and lignin contents in Eucalyptus globules using near infrared reflectance 
Sarkanen,ysis. J. of ${ }_{\mathrm{K}}^{\mathrm{W}}$.; $\mathrm{H}$. M. Chang. and Technol. 24:55-67). Species variation in lignins infrared spectra of guaiacyl and sringyl models. Tappi. 50: 572-575..I.

Silverstein, R.M and F.X.Webster (1998). Infrared spectrometry in spectrometric identification of organic compounds.6th Ed. John wiley \& sons Ins.: New York. 71-143.Socrates,G.(1994). Infrared group frequencies. Wiley and sons New York., 370-381.

Stark, N.M and M. Laurent matuan (2004). Surface chemistry changes of weathered HDPE/ wood flour composites studied by XPS \& FTIR spectroscopy. Polymer degradation and stability 86: 1-9.

White, G. Robert (1964) . Handbook of industrial infrared analysis. Library of congress card No. 647506. Plenum press, New York -USA. Page 188-197; Spectra-tructure correlation.

Wallis, A.F.A.; R.H.Wearne and P. J. Wright (1996). Analytical characteristics of lantation Eucalypt woods relating to kraft pulp yields. Appita J., 49: 427-432. 